\title{
Exploring Ways to Overcome Barriers to Mammography Uptake and Retention among South Asian Immigrant Women
}

Ahmad F, Jandu B, Albagli A, Angus JE \& Ginsburg O

"This is the peer reviewed version of the following article:

Ahmad F, Jandu B, Albagli A, Angus JE \& Ginsburg O. Exploring ways to overcome barriers to mammography uptake and retention among South Asian immigrant women. Health \& Social Care in Community 2013 January; 21(1); 88-97.

has been published in final form at:

DOI: 10.1111/j.1365-2524.2012.01090.x

This article may be used for non-commercial purposes in accordance with Wiley Terms and Conditions for Self-Archiving." 


\begin{abstract}
South Asians comprise one of the fastest growing immigrant groups in North America. Evidence indicates that South Asian (SA) immigrant women are vulnerable to low rates of breast cancer screening. Yet, there is a dearth of knowledge pertaining to socio-culturally tailored strategies to guide the uptake of screening mammography in the SA community. In 2010, the authors conducted semi-structured focus groups to elicit perspectives of health and social service professionals on possible solutions to barriers identified by SA immigrant women in a recent study conducted in the Greater Toronto Area. Thirty-five health and social services staff members participated in five focus groups. The discussions were audio taped and detailed field notes were taken. All collected data was transcribed verbatim and thematic analysis was conducted using techniques of constant comparison within and across the group discussions. Three dominant themes were identified: 1) "Target and Tailor" focused on awareness-raising through multiple direct and indirect modes or approaches with underlying shared processes of involving men and the whole family, use of first language, and learning from peers; 2) "Enhancing Access to Services" included a focus on 'adding ancillary services' and 'reinforcement of existing services' including expansion to a one-stop model; and 3) "MetaCharacteristics" centred on providing 'multi-pronged' approaches to reach the community, and 'sustainability' of initiatives by addressing structural barriers of adequate funding, healthcare provider mix, inter-sectoral collaboration, and community voice. The findings simultaneously shed light on the grass-roots practical strategies and the system level changes in order to develop efficient programmes for the uptake of mammography among SA immigrant women. The parallel focus on the "Target and Tailor" and "Enhancing Access to Services" calls for coordination at the policy level so that multiple sectors work jointly to streamline resources, or meta-characteristics.
\end{abstract}

Key words: immigrant, women, mammography, barriers; focus groups; Canada 


\section{Bullets Section}

What is known about this topic?

- Rates of mammography are low for immigrant women who belong to ethnic minority communities, including South Asians

- Multiple barriers to the uptake and retention of mammography within these communities have been identified.

What this paper adds?

- Identification of efficient ways to address these barriers

- Perspective of health and social service frontline professionals working with the South Asian immigrant community

- The parallel emphasis on programme 'targeting and tailoring' and 'enhancing access to already available services' calls for a comprehensive inter-sectoral response 


\section{INTRODUCTION}

Breast cancer is the most common cancer, and the second most common cause of death from cancer in Canadian women, accounting for $15 \%$ of all cancer deaths in this population (Canadian Cancer Society 2008). The Ontario Breast Screening Programme (OBSP) recommends screening with bilateral mammograms every two years for average-risk women aged 50 to 69 years (Cancer Care Ontario 2011). Screening mammography can help reduce breast cancer mortality by detecting cancer at an early stage and allowing for early treatment (Cancer Care Ontario 2007, U.S. Preventative Task Force 2009). Yet, screening rates in the province have held at $\sim 65 \%$, and certain subgroups of women remain under-screened in most jurisdictions. A recent integrative review of Canadian studies identified membership in an ethnic minority group as the leading barrier to screening mammography (Hanson et al. 2009). This is consistent with studies using geographical information systems demonstrating low rates of mammography in neighbourhoods with high immigrant population density (Glazier et al. 2004). Others report a vulnerability of South Asian immigrant women to low rates of breast cancer screening (Ahmad et al. 2005, Choudhry et al. 1998, Maxwell et al. 2001, Meana et al. 2001). However, there is a dearth of knowledge pertaining to older South Asian immigrant women to guide the development of socioculturally tailored strategies for uptake of screening mammography.

For the first time in Canadian history, the national census of 2006 revealed that South Asian Canadians represented the most prevalent visible minority group (Statistics Canada 2008). The term South Asian (SA) refers to people originating from the countries of India, Pakistan, Bangladesh, Sri Lanka, Nepal and Bhutan. South Asian immigrants form one of the fastest growing immigrant groups in North America. In Canada, the number of SA immigrants rose by 37\% between 1996 and 2002 (Statistics Canada 2003). This trend is likely to persist in Canada, due to its ongoing immigration policies driven by its aging population and declining birth rate. This makes it imperative to understand reasons and possible solutions for the low uptake of mammography among SA immigrant women.

Recently, we examined the barriers to screening mammography among older SA immigrant women (Ahmad et al. 2011) using a participatory approach of Concept Mapping. The women identified eight clusters of barriers to mammography: (1) Dependence on family; (2) Ease of access to mammogram centre; (3) Language and transportation; (4) Access to doctor, preferences and 'system'; (5) Fears; (6) Self care; (7) Popular beliefs and practices; (8) Knowledge. As a next step, we sought to gather the perspectives of health and social service professionals on possible solutions to address these barriers, by conducting focus group discussions. The overarching aim was to identify feasible strategies and processes to improve breast cancer screening among SA immigrant women. In addition to the generation of knowledge, we anticipate that such engagement of frontline professionals will enhance the socio-cultural sensitivity of public health policy on cancer screening among minority women in Canada.

\section{METHODS \\ Design}

We used the qualitative research method of semi-structured focus groups (Morgan \& Krueger 1998). This approach is particularly useful when the topic is not socially sensitive and group discussion could lead to deeper insights due to a 'cuing' phenomenon which fosters critical 
interaction among participants. Group discussions are also helpful to explore topics that are not extensively understood, such as interventions tailored to the needs of immigrant women (Bloor et al. 2001). Finally, focus groups are open-ended and less structured than surveys, and can elicit a more textured set of responses for deeper insights (Morgan \& Krueger 1998) and simultaneous generation of new knowledge and interpretation of findings. For this study, we obtained approval from the University of Toronto Health Sciences Research Ethics Board.

\section{Participants and Setting}

Community-based professionals from the public health and social service agencies were eligible if they had experience working with SA immigrant communities in the Greater Toronto Area (GTA), Canada. The GTA is a diverse metropolitan area; immigrants comprise more than $45 \%$ of the GTA population, compared to $20 \%$ nationally. According to the Statistics Canada census for 2006, there are 700,000 Toronto residents who identify themselves as SAs and they account for $54 \%$ of all SAs in Canada (Statistics Canada 2007). SA residents represent $31.5 \%$ of all visible minorities in Toronto, and comprise $13.5 \%$ of Toronto's total population.

\section{Procedure of Focus Groups}

In 2010, we first approached the management team of the potential agencies in GTA and those who showed interest were asked to send the study invitation to their staff as potential participants. Willing staff contacted the research team, who organised focus groups at a place and time convenient to participants. In total, we conducted five focus groups with 35 professionals over a period of three months. There were two groups with staff from public health units and three with social service agencies.

The focus group discussions were 90 to 120 minutes in duration and we served light refreshments. All participants provided written consent and completed a brief demographic survey prior to each session. The moderator (F.A. and O.G.) first presented the eight clusters of barriers to uptake of mammography from the concept-mapping study. The moderators were involved in data collection for the concept-mapping study and had first hand knowledge of the previous findings. The moderator guided the discussion using open-ended questions with the following key questions:

1. What strategies would work to address these barriers in light of your experience with the community?

2. Which of these strategies hold most promise (and why) in terms of i) improving screening status, ii) feasibility to implement, and iii) added value to reduce several barriers simultaneously?

3. What recommendations would you make to policy makers?

After the session, participants were offered an honorarium of $\$ 25$ as a token of appreciation.

\section{Data Collection}

To enhance rigour and the quality of collected data, discussions in each session were audio taped and detailed notes were taken by the assistant moderator (A.A.) who had training in field research. The moderator also recorded all of the key ideas on flipcharts during each session. The moderator notes and the flipchart list were discussed at the end of session with the participants to gather their critical feedback (i.e., member check). The moderator and assistant moderator met 
after each focus group to discuss the main emergent themes and unique aspects (i.e., debriefing). All data was transcribed verbatim and entered into QSR Internationals' NVivo 8 software, to facilitate analysis. Data from the demographic surveys was entered into a statistical software programme, SPSS Statistics ${ }^{\mathrm{TM}}$ version 18, for descriptive information on the participants.

\section{Data Analysis}

Using the transcribed data, thematic analysis was conducting following the iterative phases of discovery, coding and discounting (Kvale 1996, Taylor \& Bogdan 1998). The discovery phase refers to the researcher's gradual learning of the tentative and provisional themes and concepts before coding. During this phase, the transcribed data and notes were read for striking ideas, and an initial coding scheme was developed. This was then applied to the data collected to search for recurring words, phrases, and described activities. The next level entailed review for abstract meanings to identify emerging themes and concepts. The coding phase involved bringing together and analysing all the data related to emerging themes and concepts. The analytic technique of 'constant comparison' was applied within and between focus group discussions to refine the analysis. The emergent themes and sub-themes were reviewed by all members of the research team to finalise the findings through joint work. The coding phase occurred concurrently with data discounting, which reflects a critical interpretation of the data in the context in which they were collected. This involved paying attention to details such as disconfirming statements, multiple sources of information, solicited versus unsolicited information, single versus multiple sources of information, and filtration of data through the researchers' lens of health promotion through collective action to address health disparities. This lens views health as a social good and values redistribution of resources with a recognition of difference and diversity in communities (Benhabib 1999, Fraser \& Honneth 2003). To add rigour and trustworthiness, we used multiple strategies throughout the data collection (i.e., 'debriefing' and 'member check' as described above) and analysis (i.e., 'discounting' and 'team work' to refine coding).

\section{FINDINGS}

There were thirty-five participants in the five focus groups (Table 1). The professional training of the participants included social work, nursing, counselling, health promotion, and management. All of them were fluent in the English language and 60\% spoke one of the South Asian languages (Hindi, Punjabi or Urdu). Compared to participants from the social service agencies (Group 1, 2 and $3 ; \mathrm{n}=25$ ), participants from the public health units (Group 4 and $5 ; \mathrm{n}=10$ ) had lesser experience with immigrant communities but more years of overall work experience.

We identified three cross-cutting dominant themes in the focus group discussions. The theme of Target and Tailor focused on awareness-raising and had subthemes of 'multiple modes' and 'underlying processes' weaving through these modes. The theme of Enhancing Access to Services centered on 'ancillary services', and 'reorientation of existing services'. The third theme focused on Meta-Characteristics with sub-themes of 'multi-pronged' approaches to reach the community effectively and 'sustainability' by reducing structural barriers and enhancing intersectoral collaboration. On comparing the groups conducted at the social service agencies with the groups at the public health units, it was noted that they differed in the selection of the cluster-ofbarriers to start the discussions. The former group began the discussion by focusing on those 
clusters-of-barriers which were socio-cultural in nature (e.g., Fears; Self care; Popular beliefs and practices; and Knowledge). The latter group began the discussions by focusing on the clusters which were related to health services (e.g., Ease of access to mammogram centre; Language and transportation; and Access to doctor, preferences). As the discussions evolved within groups, the participants became engaged in all of the clusters presented to them. Thus, we present here the cross-cutting themes with representative quotations from the focus groups (FG). We also highlight unique elements that we identified for the social service and the public health groups.

\section{TABLE 1 TO BE INSERTED ABOUT HERE}

\section{Theme 1: Target and Tailor}

\subsection{Subtheme: Multiple Modes}

Participants discussed several interconnected modes of awareness-raising which formed crosscutting subcategories of Direct and Indirect modes. This sub-theme was frequently discussed in the groups with representatives from the public health units and the social service agencies.

Direct mode refers to structured awareness-raising activities in which messages are communicated face-to-face by socio-culturally competent professionals or trained peers to a specific subset of the targeted community. The examples included family physicians (FP) and community mobilisers. In terms of FP, participants in all groups agreed about and heavily discussed the significance of screening recommendations made by FP because of the community's trust in them. Yet, they emphasised the need to proactively engage FP by increasing their training in preventive medicine, cultural competency, incentives, and provision of trained interpreters. Some discussed structural barriers to engage FPs such as time and volume of patients (see Theme 3).

We need to enhance their [family physician] ability and their capacity to address these issues when it comes to prevention. They need to teach their patients because again, South Asian community tends to spend more attention on what the doctor is saying. They won't listen to you and I, they will listen to their doctor. (FG3, pg. 19)

The role of community mobilisers was frequently discussed across all groups. Participants described community mobilisers as 'community leaders', 'champions' or 'lay health educators' who take responsibility for outreach and information dissemination, after receiving some training from an agency. One participant stated, "So I spoke with my [South Asian] colleague and said where do women gather and they came up with two malls... We are doing a campaign there where we're training the vendors." (FG5, pg. 18). Conceptions of community mobilisers included both volunteers and paid staff as two ends of a spectrum. Some participants discussed workshops as an effective tool for community mobilisers to meet people at their places of gathering, especially on the weekends or evenings. This was perceived to address multiple barriers simultaneously (e.g., language, place, time, and gender sensitivity) with a potential to engage SA men in specific workshops. The latter emerged as an important focus across several modes, as discussed below

Indirect mode refers to non-structured awareness-raising activities in which messages are communicated indirectly via socio-culturally specific popular media to reach a larger set of the 
targeted community. The examples included ethnic media, written material, and fairs and walks. This sub-theme was discussed frequently across all of the groups. Participants representing the social service sector placed higher emphasis on the use of ethnic media, health fairs and walks while groups representing the public health units emphasised written materials.

Participants' discussions on the role of ethnic media included radio, television, and the Internet to address language and socio-cultural barriers. This was considered to be especially useful for newcomers, homemakers, seniors and those who are hesitant to broach the topic of breast cancer because of modesty. Some discussed the need to engage cancer survivors because "stories can be beneficial". Some suggested that radio and television programmes with live phone lines should be used to engage SA men and women in a dialogue. The emphasis on interaction was also raised for the websites to offer assessment of individualised risk of cancer or watch a video clip on mammography.

The use of language specific written materials (e.g., brochures, posters, cards, fact sheets) was also frequently discussed. Participants viewed this as a medium easy to distribute in a variety of languages and settings such as clinics, community centres, religious places, grocery stores, malls, and fairs and perceived that "they're just thrilled to be able to read that" (FG5, pg 10). They discussed the need to enhance socio-cultural relevance by addressing myths, adding contact information, and using take-home formats to trigger family discussions.

...they can take it home for the kids to read [with them] and that way the whole family would be in the same loop...if it's in a small book, booklet or flyer or something they take it home [participants nodding]. (FG3, pg. 24)

Health fairs and walks to raise awareness about breast cancer were discussed in most of the focus groups. These events were closely linked to the processes of involving men, as well as the whole family in order to raise awareness of breast cancer and screening. These weekend events were also viewed as beneficial to overcome the barriers of time and transportation.

I think health fairs would work really well...maybe just for immigrant families [like one done for seniors]...that would work really well, because it's free and that's the catch. It's free, it's available they just have to walk in. (FG2, pg.23)

\subsection{Subtheme: Underlying Processes}

Participants in all groups discussed various underlying processes that weaved through multiple modes of awareness-raising discussed above. The description of the underlying mechanisms was richer in the focus groups with the representatives of the social service agencies than the public health units. The key common processes were: Involving Men, Language, Peer Learning, and Whole Family.

Involving Men was discussed in all of the focus groups to take into consideration the patriarchal norms in SA culture which often leads to a weaker social position of women than men. Several participants proposed the inclusion of female-oriented topics, such as breast cancer, during health workshops for men. This was perceived as a mechanism to remind men about women's value, to signify preventative health, and to reduce the taboo associated with breast cancer. 
Let's only invite men for the workshop. So, men can be guests and speakers...show the importance of women...how important the wife is and, you know, what her role is and how they can support. (FG1, pg. 18)

Whole family focus came out in all of the focus groups. Participants discussed the involvement of older-younger generations and men-women from the same families. This was perceived as an effective and culturally sensitive way of information sharing and even improving women's social position. Some participants discussed that South Asian women give low priority to self-care because of their strict gender based roles in the family. As a consequence, in a participant's words, "they are scared about the family, family may think that they don't take time for them" (FG 2). To overcome these challenges, participants suggested engaging families and not just under-screened women.

Language issues were discussed by participants in all of the focus groups. Several suggestions for incorporating language-specific messaging were made when talking about media, written material, workshops, fairs, and communication with physicians or community mobilisers. In the words of a participant, "If we are talking about knowledge, it is way important that it's in their own language... appropriate language so that they can read and get the knowledge [participants nodding]" (FG3, pg. 5).

Cultural Peers were discussed in several focus groups and referred to community women who were either cancer survivors or screening-compliant and facilitated the uptake of breast cancer screening among fellow women by role-modelling and story-telling in a culturally sensitive manner. The gender concordance was emphasised for the cultural peers as one participant said “...because it's our culture, South Asian ladies don't ask these sorts of questions in front of men... but if it's just a woman's programme they are open..." (FG3, pg. 13). Participants felt that cultural peers could play an important role through formal ways (e.g. guest speaker in workshops) or informal ways at social gatherings.

It is a very important fact, to learn that peer support was, is the most effective learning model amongst South Asian community...and very successful learning model. We have seen it in cancer screening, we have seen it in heart-stroke problems, we have seen it in diabetes and it really works. (FG3, pg. 10)

\section{Theme 2: Enhancing Access to Services}

The theme of enhancing access to breast cancer screening services was identified across all of the groups with sub-foci of additional ancillary services and re-orientation of existing health services. On comparing the groups including representatives of the public health units with the groups from the social service agencies, the focus on ancillary services was voiced equivocally while reorientation of existing health services was more dominant in the groups involving representatives from the public health units.

\subsection{Subtheme: Ancillary Services}

Participants in all focus groups proposed to add various ancillary services (e.g., childcare, transportation, and peer escorts) to increase uptake of cancer screening. The provision of childcare was deemed relevant to mitigate rigid care-giving roles of South Asian immigrant women, leading to practical (e.g. time) or psychological (e.g. guilt) barriers. 
And also in mammogram centres they should have some babysitting because lots of grandmas are babysitting their grandchildren...So, where are they gonna leave the child? They're gonna leave the mammogram behind then. (FG1, pg. 10)

Participants in most of the focus groups acknowledged that some senior SA immigrant women are not accessing mammography due to their limited understanding of the public transport system and language barriers, with increasing dependence on family members. To address this, several participants proposed a shuttle bus. In a participant's words:

To reduce their dependency, we can provide some transport support to them. So, they can gather to a nearby place like the Community Health Centres or their cultural gathering, congregation places, like the religious places... (FG3, pg. 18)

Building on the idea of transportation, participants in most of the focus groups brought up the need for ethno-gender concordant escorts to accompany women during their mammography visits. The escorts were perceived to facilitate women's commute, interaction with providers, and anxiety of the procedure. Participants felt that this role could be taken up by paid staff or a volunteer peer or even a friend and some discussed its routine use in some local agencies.

A community agency is helping women book appointments and they can accompany them. So, not necessarily driving them but can accompany them on public transit and provide assurance and help them with problematic stresses. It would be more instrumental to buddy them with a friend. (FG5, pg. 6)

Incentives were also discussed in all of the focus groups in order to attract SA women to mammography services and even awareness raising activities. Participants proposed offering "return tickets", "5 dollar gift cards", "bus coupons", and "free ride".

Even simple things like providing bus tickets or tokens...the other thing that comes to mind ...would be to organise [ride]. The Canadian Cancer Society has a lot of volunteers that drive people to appointments. (FG5, pg. 4)

\subsection{Subtheme: Reorientation of Existing Services}

Participants across all focus groups were critical of the efficiency of current services through mammography centres and family physician offices. They discussed the need to have flexible schedules for mammography centres by having evening and weekend appointments or even walk-in days. Some reminded their groups that such flexibility does exist at some sites but the focus should be to increase community awareness about the flexible hours. A few suggested having more mammography centres. In terms of family physicians, they discussed the need to address not only their individual level skills (e.g., preventive focus and cultural competency) but a system level issue of time constraint due to a shortage of multidisciplinary providers and a lack of incentives.

I kind of wonder where the onus should be...we put SO much onus on physicians and expect them to remember so much and maybe this mammogram stuff, doesn't belong with the physician it belongs to the community agency, it belong to a walk in clinic, it belongs to a programme [where]... you just call them, wanna make an appointment. (FG4, pg. 9)

With this recognition of the inadequacy in the current organisation of services, participants in the majority of focus groups discussed the "one-stop" model for women. Such a model was 
suggested to have multiple services, including mammography. The concept of the one-stop model included both fixed offices and mobile clinics but was perceived as challenging (see Theme 3 ). Participants across groups also discussed the significance of trained interpreters.

\section{Theme: Meta-Characteristics}

Participants discussed some overarching features in order to achieve success in the activities they proposed for Target and Tailor awareness-raising and for Enhancing Access to Services. These focused on Multi-pronged approaches and Sustainability by reducing structural barriers and enhancing community engagement and inter-sectoral collaboration. The sub-themes of the Multipronged approach and Sustainability through sustained funds were frequently discussed and strongly emphasised in the groups involving the social service agencies, compared to the groups involving the public health units. The latter group placed more emphasis on the Sustainability through structural engagement and collaboration, compared to the former group.

\subsection{Subtheme: Multipronged}

Multipronged efforts refer to participant suggestions to develop comprehensive health promotion programmes to address many barriers at the same time. They also recognised that knowledge building is the essential first step but inadequate in itself.

I think awareness is actually the first step, nobody is going to do anything if they don't know and if they don't believe. Then, we need to have those practical multipronged approach to actually support people to do...mammograms and breast screening. (FG3, pg. 25)

From a professional stand point it's gonna be a systematic approach...[with] a number of prongs working at this. (FG3, pg. 22)

\subsection{Subtheme: Sustainability}

Participants in many groups discussed the need for sustainability in efforts to address cancer under-screening among SA immigrant and other vulnerable communities. They focused on system level changes in 'unstable funding', 'provider mix', 'inter-sectoral collaboration' and 'community voice' to overcome structural barriers.

Unstable funding was identified by the participants in all focus groups as a significant structural barrier leading to projectisim (i.e. short term ad hoc projects) and loss of trust in the community about the availability of support services for longer period of time. To address this, some proposed partnerships among various service bodies and others wanted local representative counsellors and politicians to focus on the regional allocation of funds. A few proposed a review of the three-month wait period policy applied to new immigrants to become eligible for the universal health coverage.

So, if we can do this kind of programming on a consistent basis out of the, the regular budget, instead of a pilot project.... that would be good...because these projects build the trust and credibility amongst these communities and when we stop they go back to where they started. (FG3,pg. 24)

\section{Structuring Engagement and Collaboration}

Participants discussed ways to enhance community engagement and collaboration between sectors. For example, health care provider mix and lack of incentives were perceived as structural barriers. Some proposed "tax breaks" or the provision of billing code information to engage 
family physicians in cancer screening. One participant said that "they are business oriented" and this would likely get their attention. Yet, many wished to have more nurse practitioners in clinical settings though some were critical of this and emphasised the need to have a culture of collaboration.

Well I think the whole idea of either the nurse educator, nurse practitioner, that kind of a thing, making it more accessible to people." (FG4, pg. 28) Another stated "Because they [nurse practitioners] generally have more time, they might not be as rushed....and maybe it's not quite so disease focused." (FG4, pg. 16) "You need to have a system that will accept that collaboration, will fund that collaboration... and then promote it and make sure that it happens...leadership yeah, well breaking down the silos, cause we're all in our little compartments. (FG4, pg. 19)

Likewise, many group participants pointed toward the need to have higher community representation in the agencies' staff and governing boards. One participant commented on making ethnic data available to support funding requests for such needs. "I think having the data available around screening that's not [available] right now, but again our policy makers are wanting to know what's going on in our own backyards" (FG4, pg. 24)

\section{DISCUSSION}

Health policy is often guided by a concern with the "supply" or availability of services but access is also determined by freedom to use health services within dimensions of availability, affordability, and acceptability (McIntyre et al. 2009, Thiede 2005). Our work directs attention to the degree of fit between the services offered (supply) and the needs of consumers (demand). Further, it places emphasis on relations of access, based on socially structured interactions between health care systems and individuals (McIntyre et al. 2009). In Canada, the universal availability of publicly funded health services facilitates access to available care by removing direct payment as one possible constraint to access. However, in our previous Concept Mapping study (Ahmad et al. 2011), SA women aged 50+ who were under or never screened for breast cancer identified eight clusters of barriers to participation in screening mammography. This suggests that, while removing the consumer obligation to directly pay for services may indeed facilitate access, relations at the interface between supply and demand may influence SA women's freedom to utilise existing health services, as well as their perceptions about the fit with their health needs.

Based on these foundations, the goal of the current study was to explore additional strategies that would improve breast screening participation in SA communities. Focus group discussions with community-based public health and social service agency professionals identified three dominant themes: 1) "Target and Tailor" focused on awareness-raising through multiple direct and indirect modes with underlying shared processes of involving men and whole family, and use of first language, learning from peers and incentives; 2) "Enhancing Access to Services" included a focus on 'adding ancillary services', and 'reinforcement of existing services' including expansion to a one-stop model; and 3) "Meta-Characteristics" centred on providing 'multi-pronged' approaches to reach the community, and 'sustainability' of initiatives by addressing structural barriers of adequate funding, healthcare provider mix, inter-sectoral collaboration, and community voice. 
Other researchers have suggested strategies similar to those grouped within our "target and tailor" approach to health education to improve the uptake of cancer screening services. Many note that information needs may be unique depending on age (Haines et al. 2010), culture (Bottorff et al. 2001, Johnson et al. 1999), and health practices (Hilton et al. 2001). It is frequently acknowledged that messaging must be carefully formulated to align with communicative patterns of the target group (Friedman \& Hoffman-Goetz 2006, Hoffman-Goetz \& Friedman 2007). At the same time, recognition of heterogeneity within a targeted group is important. Thus, it is quite possible that direct educational approaches through community mobilisers could be more beneficial for those SA immigrant women who are newcomers and/or experience language difficulties, compared to their counterparts who are established in the adopted country or have minimal issues with English proficiency and literacy. It is likely that women in the latter group could be optimally engaged in preventative screening via culturally competent family physicians. Perhaps, this explains why participants in our study perceived the community mobilisers and family physicians as equivocally important in direct awareness raising about cancer screening. Furthermore, it is increasingly recognised that the health of SA (and many other) women is deeply dependent on familial relationships and commitments, so it is important to include families in awareness raising interventions (Balneaves et al. 2007, Grewal et al 2005). However, there has been little attention to the possibility of raising awareness among SA men about cancer screening for women, perhaps because Western health teaching is often individuated - a problem if target populations are embedded in interdependent, patriarchal communities.

A very small number of projects have tried "enhancing access to services" through the use of strategies such as transportation assistance, child care services and peer support (FrankStromborg et al. 1998, Mayo et al. 2004). Patient navigator programmes were originally introduced to reduce disparities in breast cancer detection and treatment (Vargas et al. 2008) and the REACH 2010 team successfully tested the effect of community health navigators on breast and cervical screening for women from several ethnic communities in California (Ngoc Nguyen et al. 2008). Navigators were members of the target communities who fulfilled several functions, including the development of educational materials, liaison with community groups, creation of culturally relevant incentives, and accompaniment of women on their screening appointments. Another research group reported on the redesign of existing services to appeal to specific ethnic populations. They stressed that the success of dedicated services is not guaranteed and depends on continuous program evaluation and community outreach (Grewal et al 2004). A systematic review of access interventions indicates that culturally tailored interventions or those addressing financial or logistical barriers are more effective than education or reminder-based interventions among women with few financial resources (Masi et al 2007). Thus, our participants are astute in suggesting material support for screening, as well as accompaniment, and transportation to appointments.

There is little evidence about the costs and sustainability of institutionally based, culturally tailored interventions (Beach et al. 2006). There are indications that nurse-led programs, such as those offering nurse practitioner services, are often more cost and time effective than interventions that target physicians (Chin et al. 2007). Further, the benefits of trained interpreters needs to be examined in future research. There is strong evidence to support interventions that are "multifaceted, intensive, and include face-to-face contact and interaction between interventionists 
and participants" (Cooper et al 2002, p 484; see also Beach 2006). Our participants were sceptical of simple remedies and short term remedies, and their views align with the assertion that, without simultaneous quality improvement and sustained change on multiple levels of health service, there can be no significant resolution to access disparities (Chin et al. 2007). This also suggests new avenues for research with SA communities, because existing studies of complex interventions fail to indicate the effects of discrete components, nor do they fully reveal the potential for linking the resources of community and health services systems (Beach et al. 2006, Chin et al. 2007). Our work offers solid foundations for the design of interventions that bridge both systems to improve SA women's access to breast health services.

The qualitative nature of our study warrants caution in the applicability of the findings to other settings. Participant perspectives are unique to the metropolitan context where they had experience working with immigrant communities. Although participants represented several professional domains (e.g., nursing, social work, health promotion and community outreach), we observed higher level of eagerness to participate in this study by the social service agencies than the public health units. Perhaps, this is explained by their nature of work. The social service agencies are involved with the communities on an on-going basis while the public health units offer periodic community outreach. Future research should allocate more time to the recruitment phase for adequate representation of the diverse sectors. Further, it is important to include family physicians who offer cancer screening and advice on prevention and health promotion.

Participant discussions on "structuring engagement and collaboration" could have benefited from further probing. Future research is needed to advance understanding about inter-sectoral coordination for optimal use of resources with a meaningful impact on the uptake of breast cancer screening. It is also important to acknowledge that immigrants from South Asia may not be alike across the globe due to country-specific immigration policies. The Canadian immigration policy has adopted a scoring system since 1967 where a primary applicant is assessed for the professional skills required by the country. Yet, immigrant women especially from South Asia often arrive as dependents with no scoring requirements. This may reduce the cross-country differences for SA immigrant women.

\section{Conclusion:}

The findings simultaneously shed light on grass-roots practical strategies and system level changes to develop efficient programmes for the uptake of mammography among SA immigrant women. Participants' focus on the sustainability of efforts and ways to achieve this points towards much needed policy action by multidisciplinary dialogue and community engagement to streamline resources by inter-sectoral coordination. 
Table 1: Group Description

\begin{tabular}{|c|c|c|c|c|c|}
\hline & \multicolumn{3}{|c|}{ Social Service Agencies } & \multicolumn{2}{|c|}{ Public Health Units } \\
\hline & $\begin{array}{l}\text { Group 1 } \\
(\mathrm{N}=9)\end{array}$ & $\begin{array}{c}\text { Group } 2 \\
(N=6)\end{array}$ & $\begin{array}{l}\text { Group 3 } \\
(\mathrm{N}=10)\end{array}$ & $\begin{array}{c}\text { Group } 4 \\
(\mathrm{~N}=6)\end{array}$ & $\begin{array}{c}\text { Group } 5 \\
(\mathrm{~N}=4)\end{array}$ \\
\hline Profession & $\begin{array}{l}\text { four social } \\
\text { workers; } \\
\text { four } \\
\text { community } \\
\text { counselors; } \\
\text { one admin } \\
\text { support }\end{array}$ & $\begin{array}{l}\text { two managers } \\
\text { or coordinators; } \\
\text { four volunteer } \\
\text { or students }\end{array}$ & $\begin{array}{l}\text { five social } \\
\text { workers; four } \\
\text { managers or } \\
\text { coordinators; one } \\
\text { dietitian }\end{array}$ & $\begin{array}{l}\text { four nurses; two } \\
\text { health promoters }\end{array}$ & four nurses \\
\hline Age & $\begin{array}{l}\text { four } 35-45 \\
\text { years and } \\
\text { five } 45-55 \\
\text { years old }\end{array}$ & $\begin{array}{l}\text { two less than } \\
35 \text { years, two } \\
35-45 \text { years, } \\
\text { and two over } \\
55 \text { years old }\end{array}$ & $\begin{array}{l}\text { four less than } 35 \\
\text { years, two } 35-45 \\
\text { years, three } 45-55 \\
\text { years, and one } \\
\text { over } 55 \text { years old }\end{array}$ & $\begin{array}{l}\text { three less than } 35 \\
\text { years, one } 35-45 \\
\text { years, one } 45-55 \\
\text { years and one } \\
\text { over } 55 \text { years old }\end{array}$ & $\begin{array}{l}\text { one } 35-45 \\
\text { years and } \\
\text { three } 45-55 \\
\text { years old }\end{array}$ \\
\hline $\begin{array}{l}\text { South Asian } \\
\text { Language }\end{array}$ & six & $\operatorname{six}$ & nine & none & none \\
\hline $\begin{array}{l}\text { Work } \\
\text { Experience } \\
\text { (years) }\end{array}$ & $\begin{array}{c}\text { median } 8 \\
\text { mode } 3\end{array}$ & $\begin{array}{c}\text { median } 3 \\
\text { mode } 1\end{array}$ & $\begin{array}{c}\text { median } 3 \\
\text { mode } 2\end{array}$ & $\begin{array}{c}\text { median } 6.7 \\
\text { mode } 3\end{array}$ & $\begin{array}{c}\text { median } 27.5 \\
\text { mode } 30\end{array}$ \\
\hline $\begin{array}{l}\text { Work with } \\
\text { Immigrant } \\
\text { Communities } \\
(\%)\end{array}$ & $\begin{array}{l}\text { two } 25- \\
50 \% \text { and } \\
\text { seven over } \\
50 \%\end{array}$ & $\begin{array}{l}\text { two } 25-50 \% \\
\text { and four over } \\
50 \%\end{array}$ & $\begin{array}{l}\text { two up to } 25 \% \\
\text { two } 25-50 \% \\
\text { six over } 50 \%\end{array}$ & $\begin{array}{l}\text { one up to } 25 \% \\
\text { four } 25-50 \% \\
\text { one over } 50 \%\end{array}$ & $\begin{array}{l}\text { one up to } \\
25 \% ; \text { three } \\
25-50 \%\end{array}$ \\
\hline
\end{tabular}




\section{References}

Ahmad, F., Cameron, J. I., \& Stewart, D. E. (2005) A tailored intervention to promote breast cancer screening among South Asian immigrant women. Social Science \& Medicine 60 (1), 575-586.

Ahmad, F., Mahmood, S., Piekiewics, I., MacDonald, L., \& Ginsburg, O. (2011) A Concept Mapping of study of barriers and solutions to uptake of mammography among South Asian immigrant women. Journal of Immigrant and Minority Health, online May.

Balneaves, L. G., Bottorff, J. L., Grewal, S. K., Naidu, P., Johnson, J. L., \& Howard, A. F. (2007) Family support of immigrant Punjabi women with breast cancer. Family and Community Health 30 (1), 6-28.

Beach, M. C., Gary, T. L., Price, E. G., Robinson, K., Palacio, A., \& Cooper, L. A. (2006) Improving healthcare quality for racial/ethnic minorities: A systematic review of the best evidence regarding provider and organizational interventions. BMC Public Health 6, e104.

Benhabib, S. (1999) Citizens, residents, and aliens in a changing world: Political membership in the global era. Social Research 66 (3), 709-744.

Bloor, M., Frankland, J., Thomas, M., \& Ronson, K. (2001) Focus Groups in Social Research: Introducing Qualitative Methods. Sage, Thousand Oaks, California.

Bottorff, J. L., Balneaves, L. G., Sent, L., Grewal, S. K., \& Browne, A. J. (2001) Cervical cancer screening in ethnocultural groups: Case studies in women-centered care. Women and Health 33 (3-4), 29-46.

Canadian Cancer Society (2008) Canadian Cancer Statistics. Canadian Cancer Society and National Cancer Institute of Canada, Toronto. URL: http://www.cancer.ca/

Cancer Care Ontario (2007) Insight on Breast Cancer: New and information on breast cancer and screening in Ontario. Canadian Cancer Society (Ontario Division), Toronto, Canada

Cancer Care Ontario (2011). Action Cancer Ontario. URL http://www.cancercare.on.ca

Chin, M. H., Walter, A. E., Cook, S. C., \& Huang, E. S. (2007) Interventions to reduce racial and ethnic disparities in health care. Medical Care Research and Review 64 (5), 7S-28S.

Choudhry, U. K., Srivastava, R., \& Fitch, M. I. (1998) Breast cancer detection practices of south Asian women: knowledge, attitudes, and beliefs. Oncology Nursing Forum 25 (10), 16931701.

Cooper, L. A., Hill, M. N., \& Powe, N. R. (2002) Designing and evaluating interventions to eliminate racial and ethnic disparities in health care. Journal of General Internal Medicine 17 (6), 477-486. 
Frank-Stromborg, M., Wassner, L. J., Nelson, M., Chilton, B., \& Wholeben, B. E. (1998) A study of rural Latino women seeking cancer-detection examinations. Journal of Cancer Education: The Official Journal of the American Association for Cancer Education 13, (4), 231-241.

Fraser, N. \& Honneth, A. (2003) Redistribution or recognition? a political-philosophical exchange. Verso, London, UK.

Friedman, D. B. \& Hoffman-Goetz, L. (2006) Assessment of cultural sensitivity of cancer information in ethnic print media. Journal of Health Communication 11 (4), 425-447.

Glazier, R. H., Creatore, M. I., Gozdyra, F. I., Steele, L. S., \& Boyle, E. 2004, "Geographic methods for understanding and responding to disparities in mammography use in Toronto, Canada. Journal of General Internal Medicine 19 (9), 952-961.

Grewal, S., Bottoorff, J. L., \& Balneaves, L. G. (2004) A pap test screening clinic in a South Asian community of Vancouver, British Columbia: Challenges to maintaining utilization. Public Health Nursing 21 (5), 412-418.

Grewal, S., Bottoorff, J. L., \& Hilton, B. A. (2005) The influence of family on immigrant South Asian women's health. Journal of Family Nursing 11 (3), 242-263.

Haines, R. J., Bottorff, J. L., Mckeown, S. B., Ptolemy, E., Carey, J., \& Sullivan, K. (2010) Breast cancer massaging for younger women: Gender, femininity, and risk. Qualitative Health Research 20 (6), 731-742.

Hanson, K., Montgomery, P., Bakker, D., \& Conlon, M. (2009) Factors influencing mammography participation in Canada: An integrative review of the literature. Current Oncology 16 (5), 65-75.

Hilton, B. A., Grewal, S., Popatia, N., Bottoorff, J. L., Johnson, J. L., Claeke, H., \& Sumel, P. (2001) The desi ways: Traditional health practices of South Asian women in Canada. Health care for women international 22 (6), 553-567.

Hoffman-Goetz, L. \& Friedman, D. B. (2007) Assessing cultural sensitivity of breast cancer information for older Aboriginal women. Journal of Cancer Education 22 (2), 112-118.

Johnson, J. L., Bottorff, J. L., Balneaves, L. G., Grewal, S., Bhagat, R., Hilton, B. A., \& Clarke, H. (1999) South Asian women's views on the causes of breast cancer: Images and explanations. Patient Education and Counseling 37 (3), 243-254.

Kvale, S. (1996) Interviews: An introduction to qualitative research interviewing Sage Publication, Thousand Oaks, CA.

Masi, C. M., Blackman, D. J., \& Peek, M. E. (2007) Interventions to enhance breast cancer screening, diagnosis, and treatment among racial and ethnic minority women. Medical Care Research and Review 64 (5), 195S-242S. 
Maxwell, C. J., Bancej, C. M., \& Snider, J. (2001) Predictors of mammography use among Canadian women aged 50-69: Findings from the 1996/97 National Population Health Survey. Canadian Medical Association Journal 164 (3), 329-334.

Mayo, R. M., Sherrill, W. W., Crew, L., Watt, P., \& Mayo, W. W. (2004) Connecting rural Africal American and Hispanic women to cancer education and screening: The Avon Health Connector project. Journal of Cancer Education: The Official Journal of the American Association for Cancer Education 19 (2), 123-126.

McIntyre, D., Thiede, M., \& Birch, S. (2009) Access s a policy-relevant concept in low-and middle income countries. Health Economics, Policy, and Law 4 (Pt 2), 179-193.

Meana, M., Bunston, T., George, U., Wells, L., \& Rosser, W. (2001) Older immigrant Tamil women and their doctors: attitudes toward breast cancer screening. Journal of Immigrant Health 3 (1), 5-13.

Morgan, D. L. \& Krueger, R. A. 1998, The Focus Group Kit: Volumes 1-6. Sage, Thousand Oaks, California.

Ngoc Nguyen, T. U., Tanjasiri, S. P., Kagawa-Singer, M., Tran, J. H., \& Foo, M. A. (2008) Community health navigators for breast-and cervical cancer screening among Cambodian and Laotian women: Intervention strategies and relationship-building processes. Health Promotion Practice 9 (4), 356-367.

Statistics Canada (2003). Census of Population Immigration, birthplace and birthplace of parents, citizenship, ethnic origin, visible minorities and Aboriginal peoples. The Daily Issue Jan 21. URL http://www.statcan.gc.ca/daily-quotidien/030121/dq030121a-eng.htm

Statistics Canada (2008). Canada's Ethnocultural Mosaic, 2006 Census: Canada's major census metropolitan areas. Rep No. 97-562-XWE2006001. Ministry of Industry, Ottawa, Canada.

Taylor, S. J. \& Bogdan, R. (1998) Working with data: Data analysis in qualitative research, in Introduction to qualitative research methods, 3rd edn, John Wiley \& Sons, Inc., New York, NY, pp. 134-163.

Thiede, M. (2005) Information and access to health care: Is there a role for trust?. Social Science \& Medicine 61 (7), 1452-1462.

U.S. Preventative Task Force (2009) Screening for breast cancer: U.S. Preventive Services Task Force recommendation statement. Annals of Internal Medicine 151 (10), 716-726.

Vargas, R. B., Ryan, G. W., Jackson, C. A., Roriguez, R., \& Freeman, H. P. (2008) Characteristics of the original patient navigation programs to reduce disparities in the diagnosis and treatment of breast cancer. Cancer 113 (2), 426-433. 
